\title{
Estimating Biophysical Characteristics of Musk Thistle (Carduus nutans) With Three Remote Sensing Instruments
}

\author{
Mustafa Mirik, ${ }^{1}$ Karl Steddom, ${ }^{2}$ and Gerald J. Michels Jr. ${ }^{3}$ \\ Authors are ${ }^{1}$ Assistant Research Scientist, The Texas A\&M University System, \\ Texas Agricultural Experiment Station, Bushland, TX 79012; ${ }^{2}$ Assistant Professor, \\ The Texas A\&M University System, Texas AひM Research and Extension Center, Overton, TX 75684; and ${ }^{3}$ Professor, \\ The Texas A\&M University System, Texas Agricultural Experiment Station, Bushland, TX 79012.
}

\begin{abstract}
Identifying the dynamics and extent of noxious weeds in a spatial and temporal context improves monitoring, planning, and management practices. Musk thistle (Carduus nutans L.), a noxious weed, is a good candidate for detection by remote sensing platforms because it may produce a unique spectral signature due to a large, purple-red flower head. Therefore, 3 remote sensing instruments-a ground hyperspectral spectrometer, a multispectral ground radiometer, and an airborne hyperspectral imaging spectrometer-were used to establish regression models between reflected data and the biophysical parameters (density, height, flower head density, and percent ground cover) of musk thistle. The coefficients of determination $\left(R^{2}\right)$ obtained from simple regression models for vegetation indices and musk thistle biophysical variables ranged from 0.46 to 0.77 . Multiple regression models with up to 3 variables increased $R^{2}$ by an average of 0.07 . This study indicated that normalized difference and simple ratio indices can be used for specific applications such as detection of musk thistle biophysical variables in rangelands. Once applied to the image, these results will produce a map of parameters that can be used to determine the size of infestation and the reduction in rangeland productivity.
\end{abstract}

\section{Resumen}

La identificación de las dinámicas y cantidad de malezas nocivas en un contexto espacial y temporal mejora las prácticas de monitoreo, planeación y manejo. El "Musk thistle" (Carduus nutans L.), una maleza nociva, es un buen candidato para la detección con plataformas de sensores remotos porque puede producir un firma espectral única debido a su gran inflorescencia rojo-púrpura. Por lo tanto, tres instrumentos de sensores remotos: un espectrómetro hiperespectral terrestre, un radiómetro multiespectral terrestre y un espectrómetro aéreo de imágenes hiperespectrales se usaron para establecer modelos de regresión entre los datos reflejados y los parámetros biofísicos (densidad, altura, densidad de inflorescencias y porcentaje de cobertura) del "Musk thistle". Los coeficientes de determinación $\left(R^{2}\right)$ obtenidos de modelos de regresión simple para los índices de vegetación y las variables biofísicas del "Musk thistle" variaron de 0.46 a 0.77 . Los modelos de regresión múltiple hasta con tres variables incrementaron los valores de $R^{2}$ en un promedio de 0.07 . Este estudio indicó que la diferencia normalizada e índices de relación simple pueden ser usados para aplicaciones especificas tales como la detección de las variables biofísicas del "Musk thistle" en los pastizales. Una vez aplicados a la imagen, estos resultados producirán un mapa de los parámetros que puede ser utilizado para determinar el tamaño de la infestación y la reducción de la productividad del pastizal.

Key Words: hyperspectral imaging spectrometer, invasive plants, noxious weeds, remote sensing, vegetation indices

\section{INTRODUCTION}

Noxious weeds are well suited for successful exploitation of environmental resources (e.g., water, space, light, and nutrients) due to their aggressive and competitive ability. Along with having a competitive advantage in resource utilization over native species, many noxious weeds grow in the absence of natural enemies. This allows noxious weeds to easily establish and compete with native plants in the environment (Greenfield 2000). Due to these characteristics, noxious weeds usually move from small, manageable areas to large areas, reaching economically and environmentally significant levels (Greenfield 2000).

Correspondence: Mustafa Mirik, The Texas A\&M University System, Texas Agricultural Experiment Station, 2301 Experiment Station Road, Bushland, TX 79012. Email: MMirik@ag.tamu.edu.

Manuscript received 1 June 2004; manuscript accepted 10 October 2005.
One of these noxious weeds in the United States is musk thistle, or nodding thistle (Carduus nutans L.). Musk thistle is native to western Asia and southern Europe. The first record of the musk thistle in the United States is from Pennsylvania in 1853 (Rees et al. 1996). Under natural conditions, it functions as a biennial, winter annual, or an annual (Rees et al. 1996). Musk thistle flowers are terminal, solitary, up to 3 inches in diameter, and usually bent over. Flowers are deep rose, violet or purple, or occasionally white (Whitson et al. 1991). Reproduction is by seed only, with an average plant producing more than 10000 seeds (McCarty 1982; Andres and Rees 1995). Seed maturity and dispersal occur within 7 to 10 days of flowering. Seeds can germinate between 6 to 8 weeks after reaching the soil or they can stay viable in the soil for many years (Rees et al. 1996). Seeds generally germinate in the fall or between the spring and early summer. Seedlings develop into rosettes in their first year and flower the following summer (Andres and Rees 1995). 


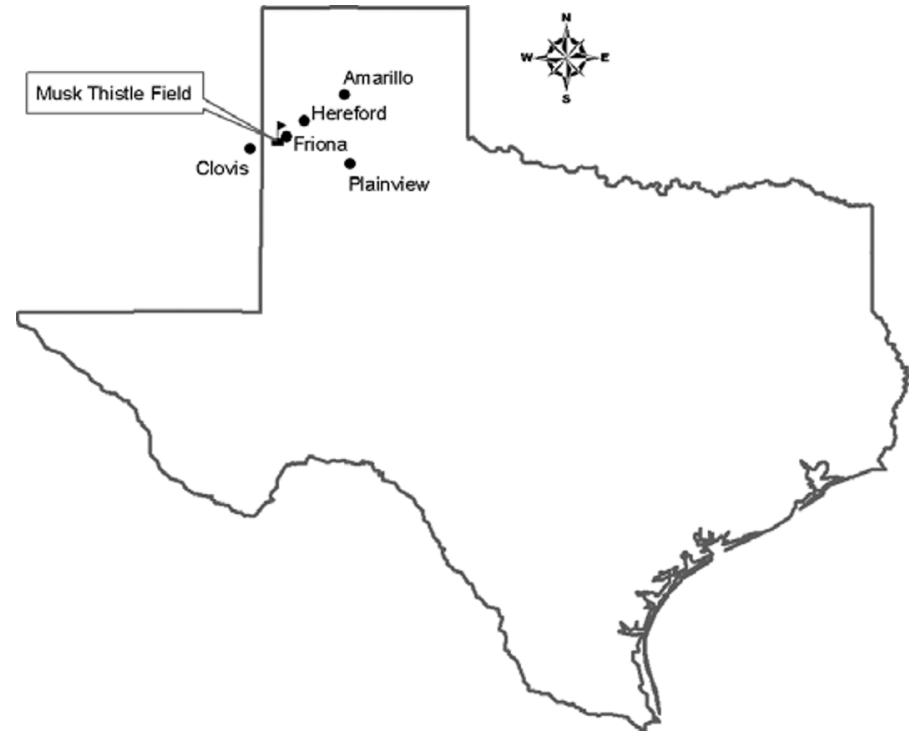

Figure 1. Location of musk thistle infestation situated near Friona, Texas.

Musk thistle infests more than 730000 ha of land in 40 states in the United States (Rees et al. 1996). It has been determined that a single musk thistle per $1.5 \mathrm{~m}^{2}$ reduces pasture yields by $23 \%$ (Rees et al. 1996; Roduner et al. 2003). It invades pasture, range and forest lands, roadsides, stream beds, waste areas, ditch banks, and agricultural fields (Whitson et al. 1991) as well as urban areas.

Monitoring the spread of musk thistle requires a repeatable, cost-effective technique. Remote sensing technologies are one of the possible solutions. Jianlong et al. (1998) reported that the definition of the problem and searching for information are the first 2 steps in remote sensing studies followed by a selection of the appropriate remote sensing instrument(s) for detection of the target object(s). Hyperspectral and multispectral algorithms, and more commonly, spectral vegetation indices, have been widely used for quantifying various biophysical variables. A number of authors (Shibayama and Akiyama 1991; Shibayama et al. 1993; Thenkabail et al. 2000) suggested that different band combinations can be used to estimate biophysical characteristics of agricultural crops as crop conditions change as a result of cultural practices, climatic conditions, and soil characteristics. For example, Thenkhabail et al. (2000) calculated normalized difference (ND) involving all possible 2-band combinations of 490 bands so as to relate them with agricultural crop characteristics. Lawrence and Ripple (1998) hypothesized that the variability in vegetation cover would be explained as much or more by a multiple linear regression equation of individual bands than any vegetation index.

Remote sensing studies have had success using broad and narrow band images to identify and distinguish some plant species, including noxious weeds (Anderson et al. 1993; Everitt et al. 1994; Carson et al. 1995; Lass et al. 1996, 2002; Lass and Callihan 1997; Parker Williams and Hunt 2002); however, musk thistle was not among them. Due to the lack of remote sensing studies on musk thistle, the present study had the following objectives: 1 ) to investigate the relationship between spectral data collected using 3 remote sensing instruments and biophysical parameters (density, percent ground cover, height, and flower head density [FHD]) of musk thistle; 2) to test all possible band combinations of the visible and near infrared (NIR) wavelengths in the ND and simple ratio (SR) indices for extracting optimal information from remotely sensed data; and 3 ) to compare the predictive power of a multiple regression model with a simple regression equation for musk thistle biophysical variables.

\section{MATERIALS AND METHODS}

A musk thistle infestation was identified in a pastureland near Friona, Texas (lat $34^{\circ} 37^{\prime} \mathrm{N}$, long $102^{\circ} 47^{\prime} \mathrm{W}$, and elevation about $1211 \mathrm{~m}$ ) (Fig. 1). An image collection flight was conducted over the study area when the musk thistle was at the peak flowering stage on 12 June 2003. An Airborne Imaging Spectrometer for Applications (AISA) version 3.0 (Spectral Imaging Ltd, Finland) mounted in a Cessna 172 airplane was used to acquire the image. Under typical conditions, the AISA can acquire between 20 and 60 bands at a spatial resolution between $1 \mathrm{~m}$ and $4 \mathrm{~m}$ per pixel. It captures 360 pixels across track with a $20^{\circ}$ field of view. Resolution along track for a single image is limited by disk space to 2 gigabytes. Downwelling irradiance is measured simultaneously via a fiber optic sensor mounted on the roof of the airplane. The down-welling irradiance is used to calibrate the image, providing units of either irradiance or reflectance. Navigation data for georectification are collected by an onboard Boeing C-MIGITS II integrated Inertial Navigation System/Global Positioning System (INS/GPS; Systron Donner Inertial Division, Concord, CA). Radiometric and geometric corrections were performed using Caligeo image preprocessing software version 1.7 (Spectral Imaging Ltd). Atmospheric correction was performed using an up-looking fiber optic sensor. Spatial resolution of the image collected over the research site was $1 \mathrm{~m}$ by $1 \mathrm{~m}$, and there were 50 bands ranging from $509 \mathrm{~nm}$ to $886 \mathrm{~nm}$ (Table 1).

On 15 June 2003, 3 days after image acquisition, ground data were obtained. A total of $711-\mathrm{m}^{2}$ ground sample plots were established in the study site. The first 25 sample plots were nonrandomly located on the basis of close proximity to prominent landmarks in order to accurately locate them within the image. High- and low-density plots were included to identify the possible extremes of the variables in the prediction models. The remaining 46 field plots were randomly selected within the site. At each plot the number of musk thistle stems, the number of flower heads, plant height, and percent ground covered by musk thistle, grass and broad-leaf species, or exposed soil were recorded.

To address the problems of coregistering ground sample and pixel locations in the 1-m resolution hyperspectral image and accuracy of INS/GPS data, ground plot locations were mapped directly to the AISA image, as is commonly done with air photos. This method was found to be superior to using a georeferenced image because georeferencing has produced errors of $\pm 2 \mathrm{~m}$ or more (Aspinall et al. 2002). Using the image on the ground, easily identifiable landmarks such as exposed soil, culverts, road corners, and scattered individual trees were exactly matched to 
Table 1. Waveband characteristics of Airborne Imaging Spectrometer for Applications mode used to acquire hyperspectral imagery of a musk thistle infestation in a pastureland near Friona, Texas, on 12 June 2003.
Table 2. Waveband characteristics of Cropscan ground multispectral radiometer used to take canopy reflectance measurements over a musk thistle infestation in a pastureland near Friona, Texas, on 15 June 2003.

\begin{tabular}{lcc}
\hline Band & $\begin{array}{c}\text { Center wavelength } \\
(\mathrm{nm})\end{array}$ & $\begin{array}{c}\text { Band width } \\
(\mathrm{nm})\end{array}$ \\
\hline 1 & 458.7 & 7 \\
2 & 509.8 & 8 \\
3 & 559.7 & 9 \\
4 & 611.9 & 10 \\
5 & 660.1 & 11 \\
6 & 708.3 & 12 \\
7 & 760.4 & 28 \\
8 & 813.2 & 32 \\
9 & 935.0 & 290 \\
\hline
\end{tabular}

a pixel in the image. The ground plots were then located close to those identified landmarks with distance and angle measurements on the ground. Using the distance and angle measurements, a pixel in the image was identified that corresponded to sample plots. This method, as described by Aspinall et al. (2002) and Mirik et al. (2005) produced matches between the pixels and sample plots that were off by less than $1 \mathrm{~m}$.

Ground spectral data at each sample plot (Fig. 1) were taken with a Cropscan multispectral field radiometer (Cropscan Inc, Rochester, MN) and an Ocean Optics hyperspectral spectrometer (Ocean Optics Inc, Dunedin, FL). The Cropscan multispectral field radiometer (MSR16) measures solar light intensity and canopy-reflected light intensity simultaneously in 9 fixed wavebands with a $28^{\circ}$ field of view. Table 2 contains the band characteristics of Cropscan multispectral field radiometer.

The Ocean Optics hyperspectral spectrometer (S2000) is a linear, charge-coupled device-array detector that is sensitive to the ultraviolet through NIR portions of the spectrum. It records reflectance from 340 through $1016 \mathrm{~nm}$ at approximately $0.33-\mathrm{nm}$ increments and a $25^{\circ}$ field of view. Due to the noise at the beginning and at the end of the spectrum, the spectral data collected by Ocean Optics hyperspectral field spectrometer in the 395-nm through $895-\mathrm{nm}$ range were used. In order to reduce the volume of data from each reading, adjacent spectral bands were averaged to $10-\mathrm{nm}$ intervals and reduced to 50 bands. The center wavelengths of the Ocean optics were $400 \mathrm{~nm}$ to $890 \mathrm{~nm}$, with a $10-\mathrm{nm}$ band width.

The band centers were rounded off to the closest $10-\mathrm{nm}$ increment; for example, $708.3 \mathrm{~nm}$ as $710 \mathrm{~nm}$ for Cropscan multispectral field radiometer. The height of the Cropscan radiometer and Ocean Optics spectrometer above the ground was set at approximately $2 \mathrm{~m}$ and $2.2 \mathrm{~m}$, respectively, in order to record the canopy reflectance from an approximately $1-\mathrm{m}^{2}$ plot.

The ND and SR indices were calculated with band combinations. By doing this, the traditionally used red and NIR wavelengths in the formulae for ND and SR indices were replaced with all possible spectral bands (visible and NIR). Indices that were best correlated with the variable(s) under consideration were chosen by performing a stepwise regression procedure. The approach exercised in this study to compute $\mathrm{ND}$ and SR indices as follows: 
Table 3. Summary statistics of field-measured variables taken in 71 $1-\mathrm{m}^{2}$ plots in the musk thistle infested pastureland located near Friona, Texas, on 15 June 2003.

\begin{tabular}{|c|c|c|c|c|c|c|}
\hline Ground measurements & Mean & Maximum & Minimum & $\mathrm{SD}^{1}$ & $\begin{array}{l}U_{C L}^{1} \\
(0.95)\end{array}$ & $\begin{array}{c}\mathrm{LCL}^{1} \\
(0.95)\end{array}$ \\
\hline \multicolumn{7}{|l|}{ Musk thistle density } \\
\hline (No. of plants/m²) & 38.4 & 113 & 2 & 28 & 45 & 31.7 \\
\hline Musk thistle height $(\mathrm{cm})$ & 67.3 & 157 & 20 & 35 & 75.6 & 59.1 \\
\hline \multicolumn{7}{|l|}{ Musk thistle flower head } \\
\hline (No. of heads/m²) & 49.5 & 94 & 2 & 23.4 & 54.9 & 43.9 \\
\hline Musk thistle cover (\%) & 37.5 & 95 & 5 & 21.9 & 42.9 & 32.8 \\
\hline Grass cover $(\%)$ & 8.5 & 60 & 0 & 12.3 & 11.4 & 5.6 \\
\hline Forb cover $(\%)$ & 2.8 & 25 & 0 & 4.3 & 3.8 & 1.7 \\
\hline Soil cover (\%) & 24.5 & 70 & 0 & 16.9 & 28.6 & 20.6 \\
\hline \multicolumn{7}{|l|}{ Standing dead } \\
\hline cover $(\%)$ & 4.2 & 40 & 0 & 7.7 & 6 & 2.4 \\
\hline Litter cover (\%) & 22.6 & 65 & 0 & 14.4 & 26 & 19.2 \\
\hline
\end{tabular}

${ }^{1} \mathrm{SD}$ indicates standard deviation; LCL, lower confidence limit; UCL, upper confidence limit.

$$
\begin{aligned}
N D & =\frac{(B i-B j)}{(B i+B j)} \\
S R & =\frac{B i}{B j}
\end{aligned}
$$

For $\mathrm{Bi}$, all the available bands greater than $700 \mathrm{~nm}$, and for $\mathrm{Bj}$, all the available bands between or greater than $400 \mathrm{~nm}$ and $\mathrm{Bi}-1$ were used for AISA, Ocean Optics, and Cropscan remote sensing instruments.

The AISA image was further analyzed using the Environment for Visualizing Images (ENVI) software (Research Systems Inc, Boulder, CO). Ground sample plots were matched to image pixels and the pixel values were extracted from the image. Data were analyzed with Statistical Analysis Systems (SAS 2003) software using the PROC STEPWISE regression analysis procedure set to the MAXR model-selection method. The MAXR model-selection method identifies the best single and multiple regression models depending on the user choice, with the highest $R^{2}$. A weighting procedure in regression analysis was performed twice, once for single-variable and once for multiple-variable regression models, for each of 4 musk thistle variables. Weighting procedure in least-square regression corrects the problem of heteroskedasticity by loglikelihood estimation of a weight that adjusts the errors of prediction. Namely, this method can sometimes improve the fit of regression models with repeated values in the predictor. Therefore, weighted regression is an appropriate method in those situations in which it is known a priori that not all observations contribute equally to the fit (S-PLUS 2001; Insightful Inc, Seattle, WA). Single factor selection was performed first and the predictors selected by stepwise regression were weighted to check whether prediction power of the model was improved using the weighting procedure. Then, higher $R^{2}$ values produced by either weighted or unweighted factors were chosen for the musk thistle variables. For the selections of multiple regression models, stepwise regression selecting 3 factors was performed secondly. Nonsignificant factors $(P>0.05)$ selected by a stepwise procedure were removed from the models, and remaining factors were weighted. Musk thistle biophysical parameters were set as the dependent variables and vegetation indices were set as the independent variables. Five sample plots fell outside of the hyperspectral image boundary; therefore, only 66 ground observations were used in regression analyses for the hyperspectral image data.

\section{RESULTS}

Musk thistle measurements included density $\left(\right.$ plants $/ \mathrm{m}^{2}$ ) from 2 to 113 , height $(\mathrm{cm})$ from 20 to 157, flower head density (heads/ $\mathrm{m}^{2}$ ) from 2 to 94 , and ground cover (\%) from 5 to 95 (Table 3). Representative mean reflectance of 15 samples measured using 3 remote sensing instruments for high $(>60 \%)$ and low $(<20 \%)$ musk thistle ground cover was consistently similar, except the reflectance switches in the range between $710 \mathrm{~nm}$ and $760 \mathrm{~nm}$ (Fig. 2). Higher ground cover captured more or reflected less light than lower cover in the range from $510 \mathrm{~nm}$ to $710 \mathrm{~nm}$ for AISA, $760 \mathrm{~nm}$ for Cropscan, and $740 \mathrm{~nm}$ for Ocean Optics sensors. The trend in higher reflectance to lesser reflectance from the lower cover switched at the red edge spectrum when compared to higher cover. Starting from 710$760 \mathrm{~nm}$, the lower cover had lesser reflectance than higher cover in the NIR spectrum (Fig. 2).

Very weak to moderate relationships were found among the 4 biophysical parameters of musk thistle by regressing one variable to another. Musk thistle density was the only variable that was transformed and used in data analyses. The logarithmic transformation worked well and improved the fit of models for skewed data, outliers, and unequal variation through squeezing and stretching (Simon 2005). Therefore, logarithmic transformation of the musk thistle density provided a higher but moderate relationship with musk thistle height $\left(R^{2}=0.52\right)$ than the raw (untransformed) data. The $R^{2}$ values were 0.24 and 0.03 between logarithmic transformation of density and cover, and flower head density, respectively. The relationship between musk thistle cover and height was moderate $\left(R^{2}=\right.$ $0.45)$. Cover and flower head density, and height and flower head density produced $R^{2}$ values of 0.32 and 0.20 , respectively. These relationships among the 4 musk thistle parameters suggest that each of the 4 musk thistle biophysical variables were sufficiently independent. In other words, the relationships among biophysical parameters of musk thistle were not high enough to affect the outcomes of remote prediction of each musk thistle variable.

Relationships between vegetation indices derived from the 3 remote sensing instruments and 4 musk thistle variables were first analyzed by stepwise linear regression with the MAXR procedure with 1 variable and then the best simple regression (1variable) models, which explained the highest variability in why the 4 musk thistle parameters were selected. The AISA-derived SR produced the same or slightly higher $R^{2}$ values than the ND for the musk thistle variables. Therefore, for simplicity, SR results are presented throughout this paper for regression models.

Predictability of the 4 musk thistle variables was improved using multiple linear regression models. Stepwise regression using the MAXR procedure and up to 3 variables were run and the best multiple regression (2- or 3-variable) models were selected based on the statistically significant spectral vegetation indices $(P<0.05)$ for predicting 4 musk thistle variables. 

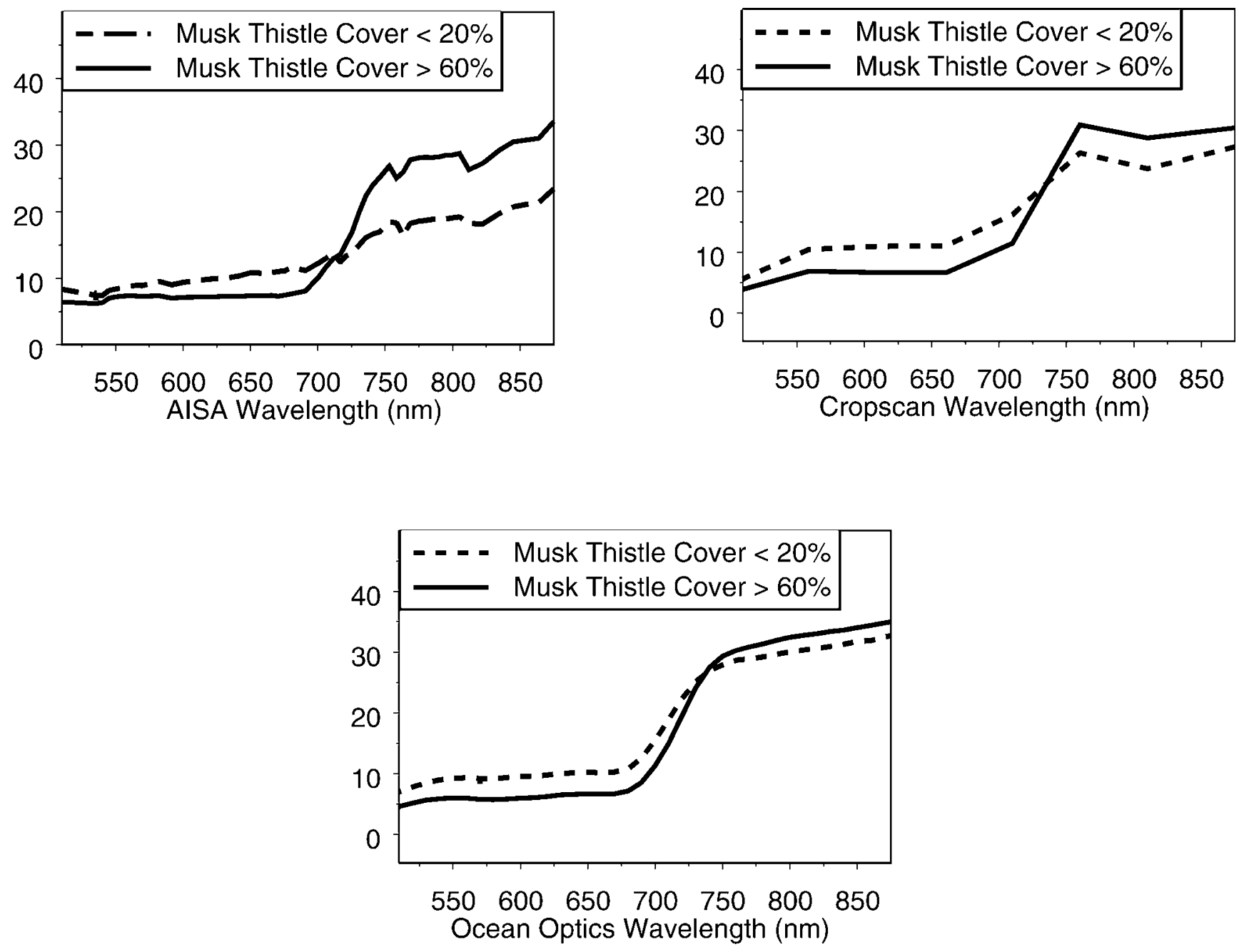

Figure 2. Mean reflectance of 15 observations for the low musk thistle percent ground cover $<20 \%$ and high percent ground cover $>60 \%$ collected using Airborne Imaging Spectrometer for Applications (AISA; upper left), Cropscan multispectral ground radiometer (upper right), and Ocean Optics hyperspectral field spectrometer (bottom).

\section{Musk Thistle Percent Cover}

Vegetation indices, regression models, and $R^{2}$ values for each of the 3 remote sensing systems for percent cover estimation are presented in Figure 3. Percent ground cover was well predicted by all 3 remote sensing data sets. About $68 \%$ and $70 \%$ of the variation in cover was explained by SRs derived from AISA $\left(\mathrm{SR}_{864 / 834}\right)$ and Cropscan $\left(\mathrm{SR}_{810 / 559}\right)$, respectively, whereas Ocean Optics-derived $\mathrm{ND}_{770,740}\left(\mathrm{ND}_{770}-740 / 770+740\right)$ accounted for $65 \%$ of the variability in cover. Ocean Opticsderived SRs and Cropscan-derived NDs were weighted using the weight procedure in SAS, whereas AISA-derived SR was not weighted. $P$ values for regression models, Cropscan- and AISAderived SRs, and Ocean Optic-derived NDs were $<0.0001$. This suggested that models, SRs, and NDs were statistically significant to predict percent cover. Slopes of the regression lines were negative for AISA and positive for Cropscan and Ocean Optics. ND 850,650 of AISA, Cropscan, and Ocean Optics explained $24 \%, 25 \%$, and $32 \%$ less variation in percent cover when compared to the best models in Figure 3, respectively. Cropscan-derived SRs, among others, exhibited the highest relationship with percent cover; therefore, SRs were computed using the same or closest wavebands of AISA and Ocean Optics sensors and compared with Cropscan SR. $R^{2}$ values generated using AISA-derived and Ocean Optics-derived SRs were 0.26 and 0.13 less than Cropscan-derived SR for the percent cover, respectively.

Table 4 that the contains information about the remote sensing instruments, multiple regression models, weighed and unweighed vegetation indices, $R^{2}$ values, and associated statistics. SRs and NDs derived from 3 remote sensing instruments produced the highest $R^{2}$ values for each model. Multiple regression models with 3 and 2 factors for AISA, Cropscan, and Ocean Optics explained about $79 \%, 73 \%$, and $69 \%$ of the variability in cover, respectively. $P$ values for all regression models and predictors were $<0.0001$.

\section{Musk Thistle Density}

Logarithmic transformation of musk thistle density was used to develop linear regression models. Figure 4 and Table 4 contain information about simple and multiple regression models, respectively. Density was well estimated with Ocean Optics- 

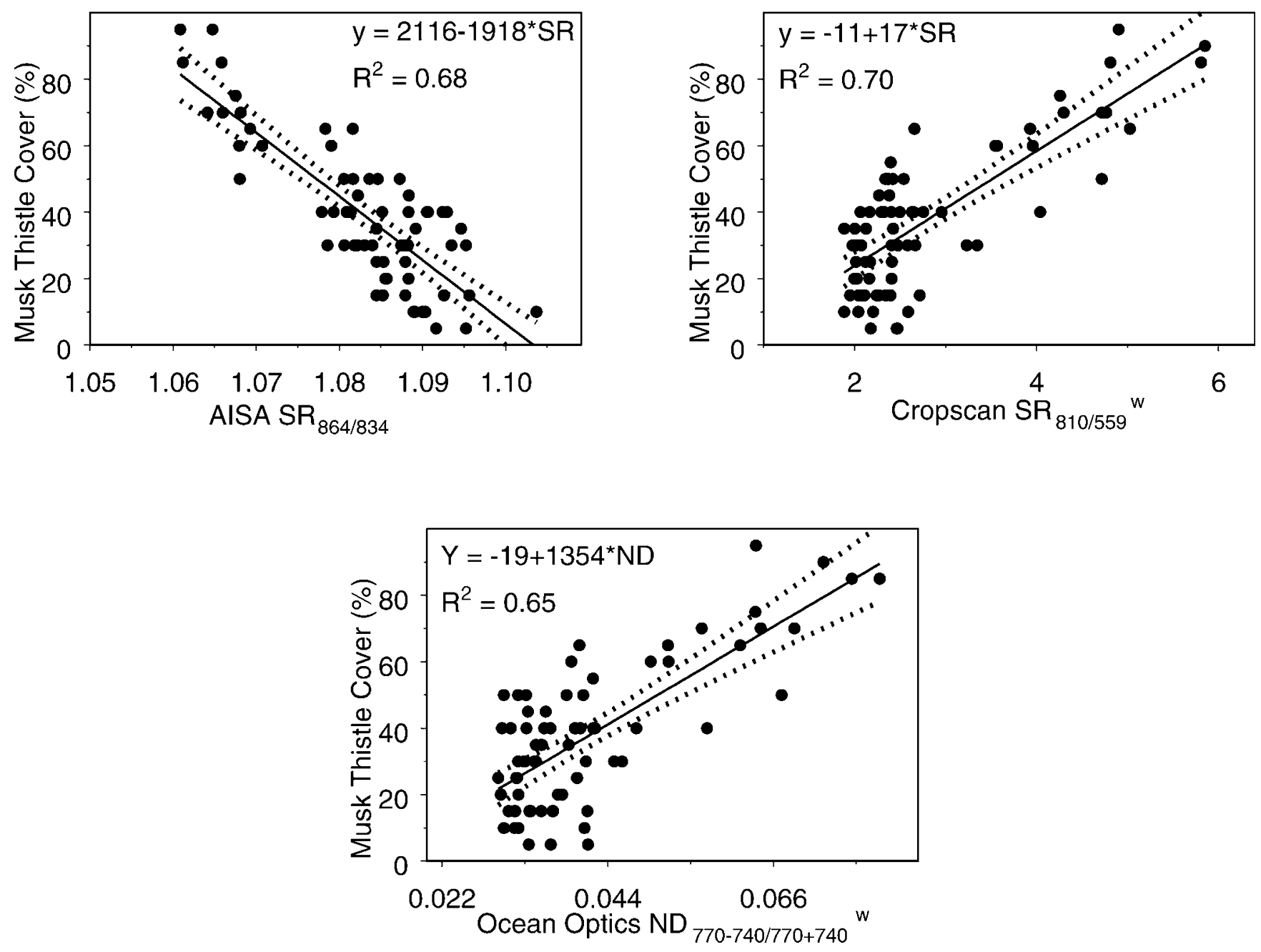

Figure 3. Scatter plot, regression line (solid), and 95\% upper and lower confidence intervals (dotted) for the highest $R^{2}$ obtained by regressing the vegetation indices against musk thistle percent cover for Airborne Imaging Spectrometer for Applications (AISA; upper left), Cropscan (upper right), and Ocean Optics (bottom) remote sensing instruments. (SR and ND: simple ratio and normalized difference indices, respectively; and ${ }^{\mathrm{W}}$, weighted SR and ND using the weight procedures in SAS 9 for Windows).

derived $\mathrm{ND}_{890,720}\left(R^{2}=0.75\right)$ followed by Cropscan-derived $\mathrm{ND}_{810,710}\left(R^{2}=0.70\right) . \mathrm{SR}_{805 / 758}$ derived from AISA were moderately related to density $\left(R^{2}=0.46\right)$ (Fig. 4). Regression models and associated parameters were highly significant $(P<0.0001)$. Both NDs derived from Ocean Optics and Cropscan were weighed, and all models had negative slopes. $\mathrm{ND}_{850,650}$ of AISA, Cropscan, and Ocean Optics produced $R^{2}$ values that were $0.27,0.11$, and 0.30 less than those models in Figure 4, respectively, for density. Ocean Optics-derived NDs among others exhibited the highest relationship with percent cover; therefore, NDs were computed using the same or closest wavebands of AISA and Cropscan sensors and compared with Ocean Optics NDs. NDs derived from AISA and Cropscan explained $23 \%$ and $19 \%$ less variation in density when compared with Ocean Optics-derived NDs, respectively.

Multiple regressions with 2 factors for Cropscan and Ocean Optics produced similar $R^{2}$ values $(0.76)$. The prediction power of the 2-variable regression model compared with the 1variable model slightly improved Cropscan NDs. The model and predictors were highly significant $(P<0.0001$ for both predictors and model). The predictability of density was improved by the 3 -variable regression model $\left(R^{2}=0.62\right)$ for the AISA data set (Table 4). Models predicting density and model parameters were statistically significant $(P<0.0001)$ for the AISA and Ocean Optics data sets (Table 4).

\section{Musk Thistle Height}

Among the musk thistle variables, the height displayed the strongest relationship with Cropscan- and Ocean Opticsderived NDs (Fig. 5 and Table 4). One-variable models using Cropscan $\mathrm{ND}_{810,559}$ and Ocean Optics $\mathrm{ND}_{890,540}$ explained about $77 \%$ and $73 \%$ of the variability in height, respectively. These models and associated parameters were statistically significant $(P<0.0001)$ and had positive slopes. The relationship between height and AISA-derived $\mathrm{SR}_{864 / 845}$ was much lower than those of Cropscan and Ocean Optics NDs $\left(R^{2}=0.54\right)$. This 1-variable model had a negative slope and was highly significant for predicting musk thistle height (Fig. 5). ND 850,650 of AISA, Cropscan, and Ocean Optics explained 19\%,3\%, and $17 \%$ less variation in height when compared with the best models in Figure 5, respectively. Cropscan-derived NDs among 
Table 4. The best multiple regression models with the associated probability statistics and coefficients of determination to predict four musk thistle variables using normalized difference vegetation index derived from Airborne Imaging Spectrometer for Applications (AISA), Cropscan, and Ocean Optics remote sensing instruments. ${ }^{1}$

\begin{tabular}{|c|c|c|c|c|c|c|c|}
\hline Instrument & Variable & Multiple regression model & $R^{2}$ & Model $P$ & $\beta_{1} P$ & $\beta_{2} P$ & $\beta_{3} P$ \\
\hline AISA & Cove & $y=1592-1004\left(S_{834 / 805}\right)-700\left(S_{845 / 812}\right)-1222\left(S_{864 / 834}\right)$ & 0.79 & $<0.0001$ & $<0.0001$ & $<0.0001$ & $<0.0001$ \\
\hline Cropscan & & $y=-51-205\left(N D_{760,661}\right)^{\mathrm{w}}+406\left(N_{810,559}\right)^{\mathrm{w}}$ & 0.73 & $<0.0001$ & $<0.0001$ & $<0.0001$ & \\
\hline Ocean Optics & & $y=-88+198\left(N D_{710,550}\right)^{w}+1918\left(N D_{780,750}\right)^{w}$ & 0.69 & $<0.0001$ & $<0.0001$ & $<0.0001$ & \\
\hline AISA & Density & $y=0.13+2\left(S_{701 / 610}\right)-19\left(S_{794 / 660}\right)+19\left(S_{812 / 758}\right)$ & 0.62 & $<0.0027$ & $<0.0001$ & 0.0007 & $<0.0001$ \\
\hline Cropscan & & $y=0.01+10\left(N D_{810,510}\right)^{w}-12\left(N D_{810,710}\right)^{w}$ & 0.76 & $<0.0001$ & $<0.0001$ & $<0.0001$ & \\
\hline Ocean Optics & & $y=6+29\left(N D_{820,790}\right)^{w}-15\left(N D_{890,720}\right)^{w}$ & 0.76 & $<0.0001$ & 0.0032 & $<0.0001$ & \\
\hline AISA & Height & $y=2561-3279\left(S_{822 / 805}\right)-1760\left(S_{822 / 815}\right)$ & 0.66 & $<0.0001$ & $<0.0001$ & $<0.0001$ & \\
\hline Cropscan & & $y=-123+431\left(N D_{760,460}\right)^{w}-1609\left(N D_{760,559}\right)^{w}+1494\left(N D_{810,559}\right)^{w}$ & 0.84 & $<0.0001$ & 0.0012 & $<0.0001$ & $<0.0001$ \\
\hline Ocean Optics & & $y=-249+340\left(N D_{770,420}\right)^{w}+2341\left(N D_{800,760}\right)^{w}$ & 0.82 & $<0.0001$ & $<0.0001$ & $<0.0001$ & \\
\hline AISA & FHD & No model selected & & & & & \\
\hline Cropscan & & $y=59-160\left(N_{710,510}\right)+460\left(N D_{710,559}\right)+892\left(N D_{810,760}\right)$ & 0.55 & $<0.0001$ & 0.0195 & $<0.0001$ & $<0.0001$ \\
\hline Ocean Optics & & $\mathrm{y}=-63+3231\left(\mathrm{NDVI}_{780,750}\right)^{\mathrm{w}}-267\left(\mathrm{NDVI}_{810,420}\right)^{\mathrm{w}}$ & 0.52 & $<0.0001$ & $<0.0001$ & 0.0001 & \\
\hline
\end{tabular}

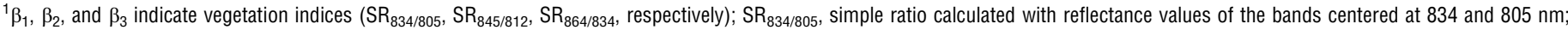

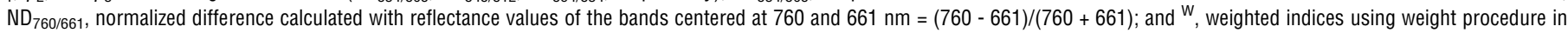
SAS 9 for Windows.

others exhibited the highest relationship with height; therefore, NDs were computed using the same or closest wavebands of AISA and Ocean Optics sensors and compared with Cropscan NDs. $R^{2}$ values generated using AISA-derived and Ocean Optics-derived NDs were 0.22 and 0.11 less than the Cropscan-derived ND for height, respectively.

Two- and 3-variable models predicting musk thistle height provided improvement over the 1-variable linear regression models. The $R^{2}$ values were $0.84,0.82$, and 0.66 for Cropscan-, Ocean Optics-, and AISA-derived SRs (Table 4). NDs and SRs were strong estimators $(P<0.0001)$ of musk thistle height, and the prediction models were statistically significant $(P<0.0001)$.

\section{Musk Thistle Flower Head Density}

FHD was poorly predicted by spectral vegetation indices compared to estimation of the other variables (Fig. 6 and Table 4). This poor estimation of FHD might be related to the low percentage of flower head cover in comparison with the $1 \mathrm{~m}^{2}$ unit area over which reflectance data were collected. Ocean Optic $\mathrm{ND}_{800,750}\left(R^{2}=0.46\right)$ and Cropscan $\operatorname{SR}_{810 / 760}\left(R^{2}=0.42\right)$ moderately predicted FHD (Fig. 6). A poor relationship was found $\left(R^{2}=0.25\right)$ only between FHD and AISA SR ${ }_{706 / 535}$. The 1 -variable models and predictors for AISA, Cropscan, and Ocean Optics were highly significant $(P<0.0001)$. All models generated using the AISA, Cropscan, and Ocean Optics spectral data had a positive slope. $\mathrm{ND}_{850,650}$ of AISA, Cropscan, and Ocean Optics produced $R^{2}$ values that were, respectively, $0.24,0.38$, and 0.46 less than those models in Figure 6 for FHD. Ocean Optics-derived NDs among others exhibited the highest relationship with FHD; therefore, NDs were computed using the same or closest wavebands of AISA and Cropscan sensors and compared with Ocean Optics NDs. NDs derived from AISA and Cropscan explained $43 \%$ and $4 \%$ less variation, respectively, in FHD when compared with Ocean Optics-derived NDs.

No multiple regression model was generated to predict FHD using AISA reflectance data because addition of more than one term into the equation did not improve the predictive ability of the model and there were no 2 or 3 statistically significant predictors. Correlation between FHD and Cropscan NDs increased about $13 \%\left(R^{2}=0.55\right)$ with a 3 -variable model compared with 1 -variable model, and a $6 \%$ increase using the Ocean Optics 2variable model over the 1-variable model was observed for FHD prediction (Table 4). These models and predictors were highly significant $(P<0.0001)$, except Cropscan $\mathrm{ND}_{710,510}$; this predictor was statistically significant $(P=0.0195)$. Findings of the present study for FHD prediction are not comparable to other research because, to the best of our knowledge, no remote sensing study dealing with FHD has been performed.

\section{DISCUSSION}

The spectra ranging from visible to NIR were very informative, and different band combinations in NDs and SRs could be used to predict the 4 musk thistle variables (Figs. 3-6 and Table 4). Cropscan-derived ND was used to develop a 2-variable predictive model for the percent cover, and an AISA-derived SR was used to develop a 3-variable regression model for the density; these were the only 2 indices for which the red wavelengths were used. For example, 2 NIR bands centered at 864 and $834 \mathrm{~nm}$ were used to compute the AISA SR, which produced the highest $R^{2}$ for the ground cover, whereas the SR of Cropscan bands centered at 810 and $559 \mathrm{~nm}$ was the best predictor for cover. The Ocean Optics ND centered at 770 and $740 \mathrm{~nm}$ was the best predictor for cover. This suggests that bands in the entire visible and NIR spectra can be used in ratiobased vegetation indices for estimating musk thistle biophysical variables.

The normalized difference vegetation index $\left(\mathrm{NDVI}_{850,650}\right)$ derived from 3 remote sensing sensors had weak to good relationships with percent cover, density, and height depending on the sensors used. However, these relationships were lower than those for NDs and SRs presented in Figures 3-6. No relationship was found between $\mathrm{ND}_{850,650}$ and FHD. The lack 

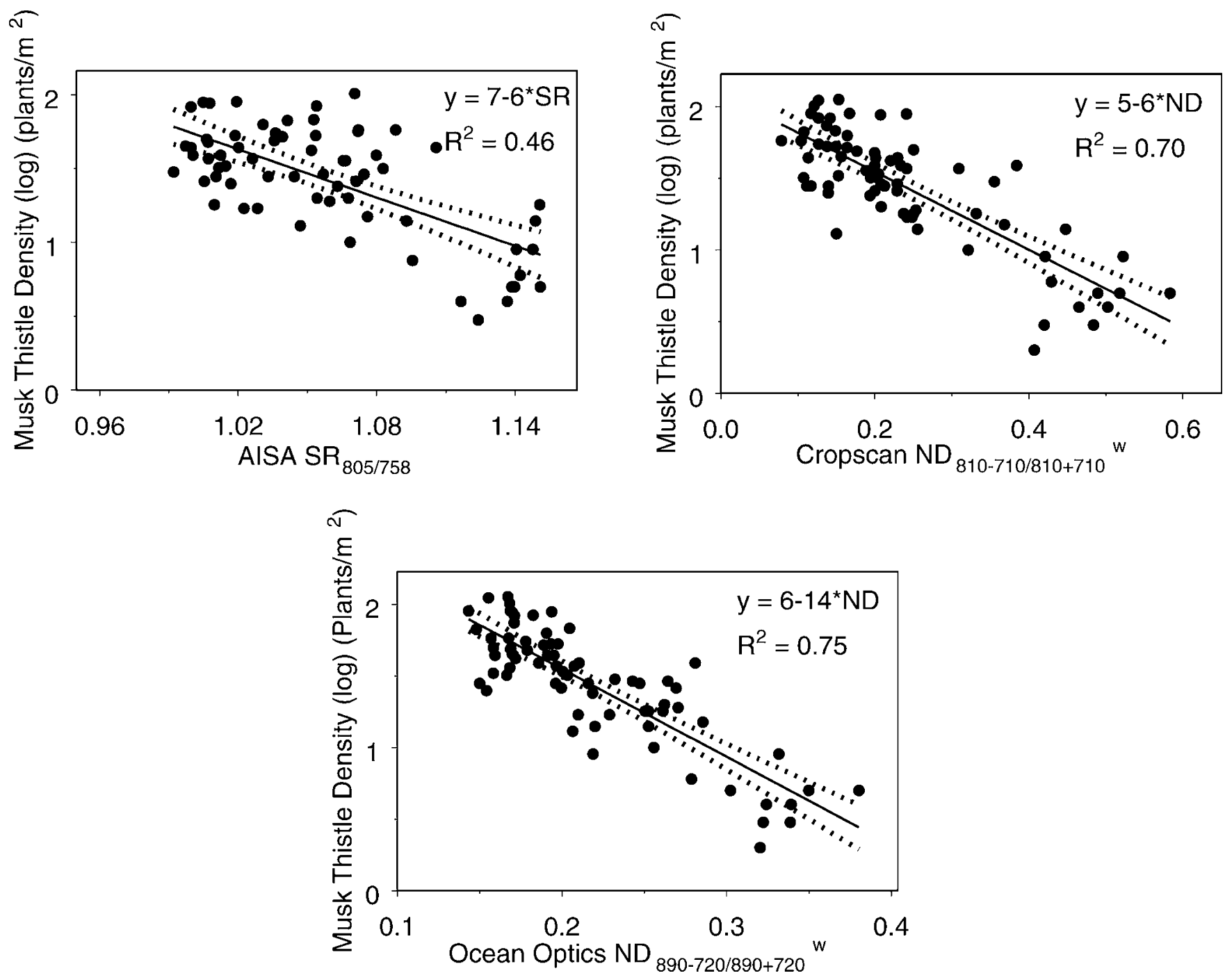

Figure 4. Scatter plot, regression line (solid), and 95\% upper and lower confidence intervals (dotted) for the highest $R^{2}$ obtained by regressing the vegetation indices against musk thistle density for Airborne Imaging Spectrometer for Applications (AISA; upper left), Cropscan (upper right), and Ocean Optics (bottom) remote sensing instruments. (SR and ND: Simple ratio and normalized difference indices, and W. Weighted ND using the weight procedures in SAS 9 for Windows).

of relationship between $\mathrm{ND}_{850,650}$ and FHD might be due to the purple-reddish color of the flower because ND ([NIR - RED] / [NIR + RED]) was designed using broad wavebands and widely used to quantify green canopies. Another example could be $\mathrm{NDVI}_{850,650}$ derived from the Cropscan sensor that exhibited higher relationships with musk thistle parameters when compared to the predictive powers of the remaining 2 instruments. Thenkabail et al. (2000) suggested 12 hyperspectral bands for studying agricultural crop characteristics and concluded that the commonly used red and NIR spectra in ND indices are not the best for predicting agricultural crop parameters. Using the same or closest wavebands of AISA, Cropscan, and Ocean Optics remote sensing instruments in NDs and SRs to estimate the same musk thistle variables usually resulted in a lower $R^{2}$ or insignificant models when compared to the best models given in Figures 3-6.

The findings of this study for musk thistle percent ground cover agree with the results of previous studies on other weed species. Parker Williams and E. Raymond Hunt, Jr (2002) carried out a study to investigate the possibility of using Airborne Visible and Infrared Imaging Spectrometer (AVIRIS) data to delineate leafy spurge distribution and predict cover of flowering leafy spurge. Good relationships between mixturetuned match filtering (MTMF) of AVIRIS hyperspectral imagery and cover of flowering leafy spurge in draw, upland, prairie, and woodland habitats were found, which had $R^{2}$ values of $0.72,0.684,0.793$, and 0.567 , respectively. In an arid environment disturbed by human activities, McGwire et al. (2000) tested the ability of remote sensing instruments to detect the percentage of green vegetation cover for areas of sparse vegetation. The researchers reported $R^{2}$ values of $0.604,0.629,0.513$, and 0.644 for narrowband ND, broadband ND, soil-adjusted vegetation index (SAVI), and modified SAVI for green vegetation cover, respectively.

The results found for musk thistle height were much higher than those found by Jakubauskas et al. (2001), and strongly agreed with the findings of Thenkabail et al. (2000). Jakubaus- 

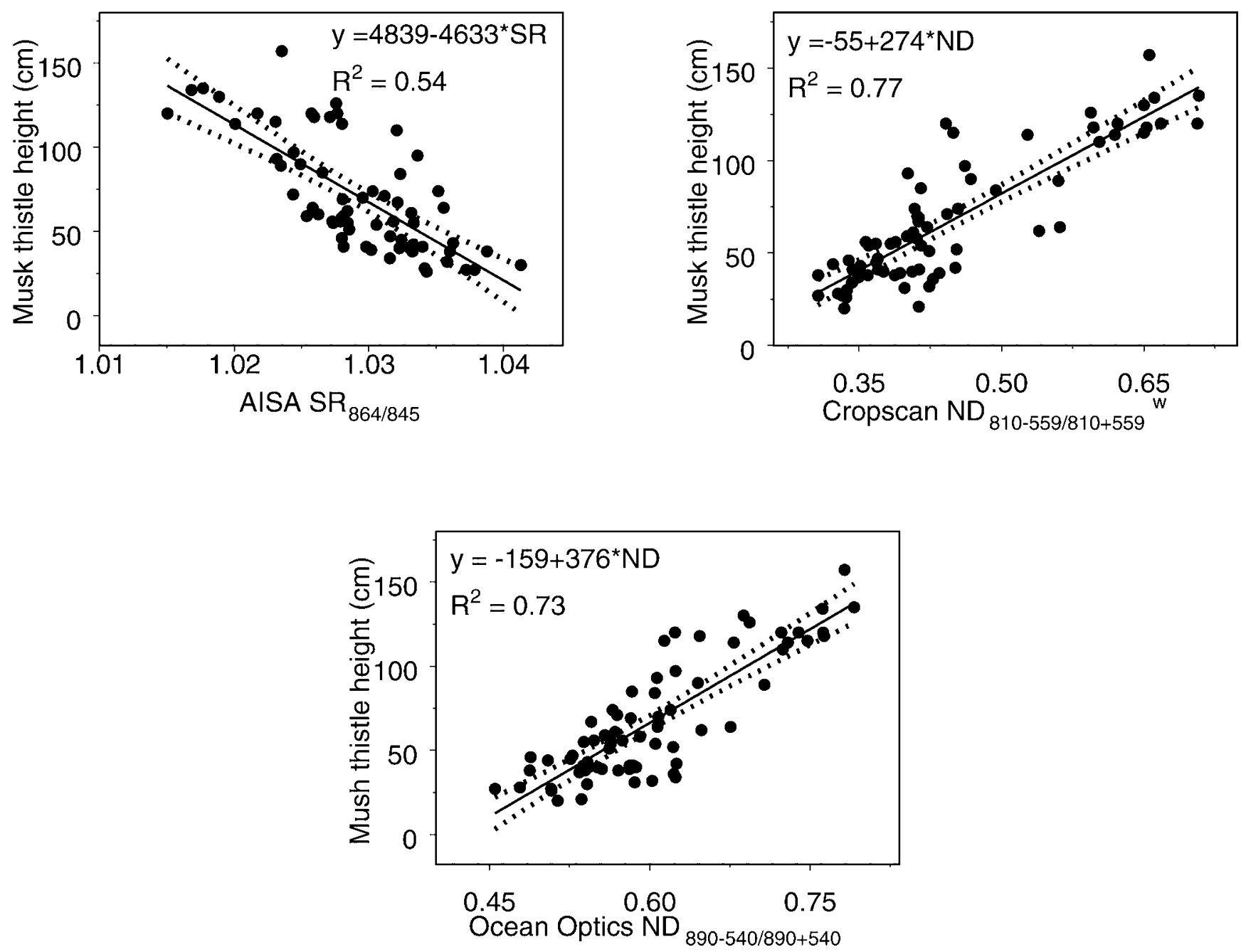

Figure 5. Scatter plot, regression line (solid), and 95\% upper and lower confidence intervals (dotted) for the highest $R^{2}$ obtained by regressing the vegetation indices against musk thistle height for Airborne Imaging Spectrometer for Applications (AISA; upper left), Cropscan (upper right), and Ocean Optics (bottom) remote sensing instruments. (SR and ND: Simple ratio and normalized difference indices, and W: Weighted ND using the weight procedures in SAS 9 for Windows).

kas et al. (2001) reported that $R^{2}$ values generated by 1 variable models fell between 0.10 and 0.38 for big sagebrush height and between 0.19 and 0.40 for low sagebrush height. Thenkabail et al. (2000) reported $R^{2}$ values of $0.78,0.77,0.52$, and 0.31 for soybean, potato, cotton, and corn heights, respectively. Like the 1-variable models predicting musk thistle height, the prediction power of the 2- and 3-variable models generated in this study was higher than those in the study by Jakubauskas et al. (2001) and similar to the findings of Thenkabail et al. (2000). $R^{2}$ values produced by multiple regression models and reported by Jakubauskas et al. (2001) were 0.43 and 0.54 for bitterbrush and big sagebrush heights, respectively. Four-variable regression models had $R^{2}$ values of $0.92,0.83,0.71$, and 0.64 for soybean, potato, corn, and cotton heights, respectively (Thenkabail et al. 2000).

Lawrence and Ripple (1998) reported multiple $R^{2}$ values of 0.75 for vegetation cover. Jakubauskas et al. (2001) studied the relationships between biophysical variables of montane sagebrush communities and multitemporal data. They concluded that remotely sensed data were useful for predicting some of the sagebrush community biophysical factors. In their study, multiple $R^{2}$ values ranged from 0.28 to 0.71 for different cover types. Thenkabail et al. (2000) considered that the STEPWISE MAXR is the best of several stepwise methods for selecting 1-, $2-$, and 3-variable models that provide the highest $R^{2}$ value. Findings of the present study for musk thistle stem and flower head density estimations are not comparable to other research because, to the best of our knowledge, no remote sensing study addressing FHD has occurred.

\section{MANAGEMENT IMPLICATIONS}

This study investigated the use of vegetation indices derived from hyperspectral and multispectral data in detecting musk thistle in a mixed pasture. Ground and aerial sensors were used over the visible and NIR ranges. Ground surveys documented percent cover, height, density, and flower head content of musk thistle in a test pasture. The results showed that musk thistle infestation could be quantified with an $R^{2}$ of $0.55-0.84$, with height giving the best data fit followed by percent cover. Aerial 

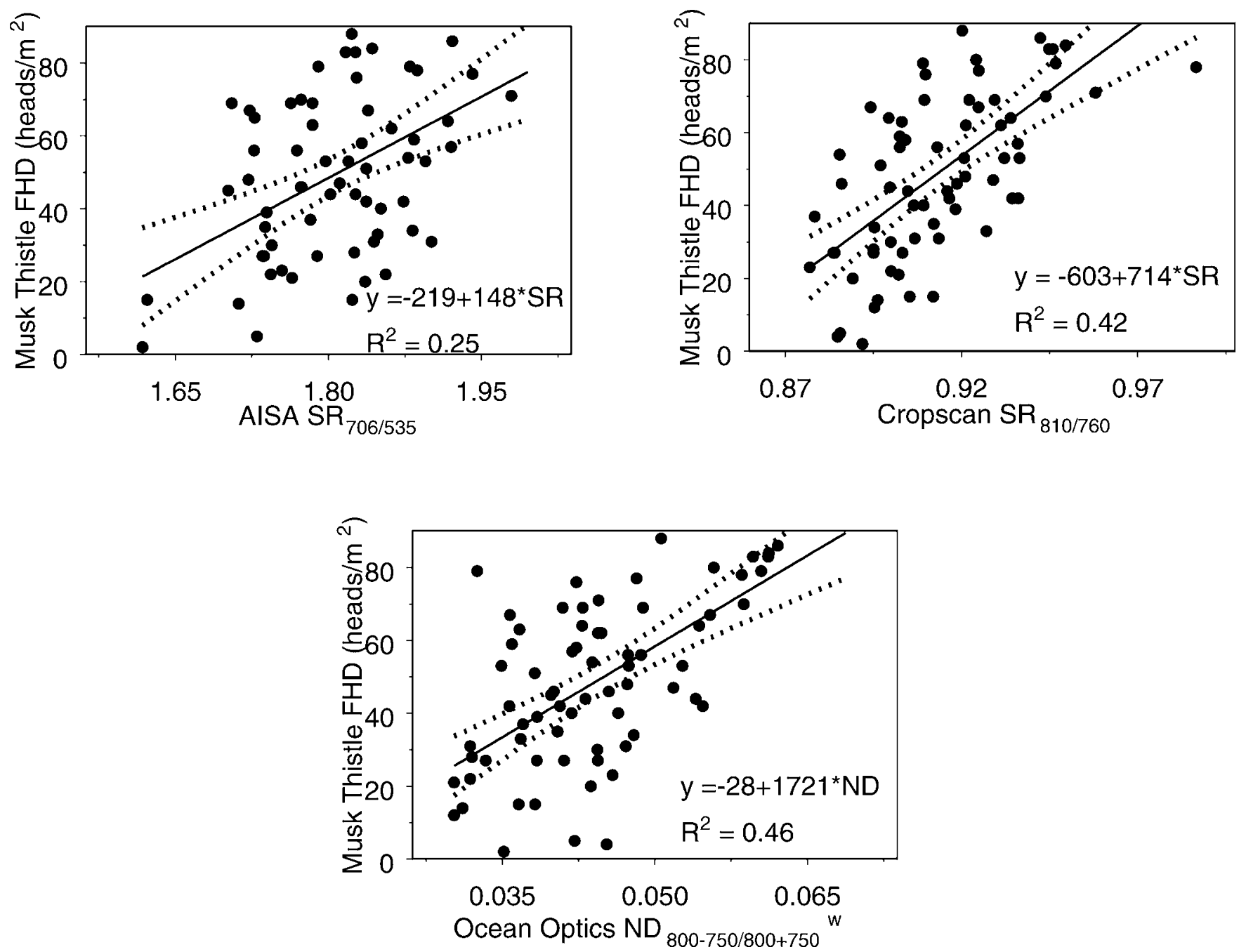

Figure 6. Scatter plot, regression line (solid), and 95\% upper and lower confidence intervals (dotted) for the highest $R^{2}$ obtained by regressing the vegetation indices against musk thistle flower head density for Airborne Imaging Spectrometer Applications (AISA; upper left), Cropscan (upper right), and Ocean Optics (bottom) remote sensing instruments. (SR and ND: Simple ratio and normalized difference indices, and W: Weighted ND using the weight procedures in SAS 9 for Windows).

sensors were as accurate as ground sensors for quantifying percent cover. Contrary to initial expectations, flower head content was moderately predicted, despite the distinctive spectral properties of the flowers. Results indicate that each instrument has the ability to capture data relating to musk thistle biophysical parameters. A stepwise regression analysis is a powerful procedure for selecting the best predictor(s) among the hundreds of associated variables highly related to estimating musk thistle parameters.

This study has shown that ground and aerial remote sensing data at $1-\mathrm{m}$ resolution resulted in moderate to high relationships with musk thistle biophysical variables. This has implications for rangeland management and productivity as follows: Using high relationships between vegetation indices and musk thistle parameters (particularly percent cover, density, and height), maps at a 1-m scale can be generated over larger areas. These maps provide spatial extent and dynamics of musk thistle over time in pastures, which can be used for monitoring, planning, and control measures. Using maps at a 1-m scale, the size of musk thistle or other weed infestations can be accurately determined through image classification. Such an image classification provides detailed spatial and temporal information on reduction in range productivity because a single musk thistle per $1.5 \mathrm{~m}^{2}$ decreases pasture yields by $23 \%$ (Rees et al. 1996; Roduner et al. 2003). The use of a $1-\mathrm{m}$ spatial resolution hyperspectral image to provide valuable estimates of certain biophysical parameters of undesirable rangeland weed species was shown in this study, and it is recommended that this methodology and technology be considered when high-scale maps are needed for rangeland research and management.

\section{ACKNOWLEDGMENTS}

We extend thanks to Thomas Marek and Terry Wheeler at the Texas A\&M University Agricultural Experiment Station in Amarillo and Lubbock, Texas; and to Jack Norland at North Dakota State University, Animal and Range Sciences, Fargo, North Dakota, for their critical review of the manuscript. Special thanks to David Jones, Sabina Kassymzhanova-Mirik, Johnny Bible, and Shana Camarata at the Texas A\&M University Agricultural Experiment Station in Amarillo, Texas, for their technical assistance. 


\section{LITERATURE CITED}

Anderson, G. L., J. H. Everitt, A. J. Richardson, and D. E. Escobar. 1993. Using satellite data to map false broomweed (Ericameria austrotexana) infestations on South Texas rangelands. Weed Technology 7:865-871.

Andres, L. A. And N. E. Rees. 1995. Musk thistle. In: J. R. Nechols, L. A. Andres, J. W. Beardsley, R. D. Goeden, and C. G. Jackson [EDs.]. Biological control in the western United States. Oakland, CA: Division of Agricultural and Natural Resources, University of California Press. p 248-251.

Aspinall, R. J., W. A. Marcus, and J. W. Boardman. 2002. Considerations in collecting, processing and analyzing high spatial resolution hyperspectral data for environmental investigations. Journal of Geographical Systems 4: 15-29.

Carson, H. W., L. W. Lass, and R. H. Callihan. 1995. Detection of yellow hawkweed (Hieracium pretense) with high resolution multispectral digital imagery. Weed Technology 9:477-483.

Everitt, J. H., J. V. Richerson, M. A. Alaniz, D. E. Escobar, R. Villarreal, and M. R. Davis. 1994. Light reflectance characteristics and remote sensing of Big Bend loco (Astragalus mollissimus var. earlei) and Wooton loco (Astragalus wootonii). Weed Science 42:115-122.

GreenfieLd, P. H. 2000. Remote sensing for invasive species and plant health monitoring. In: Detecting and monitoring of invasive species. USDA, Plant Health Conference; 24-25 October 2000; Raleigh, NC. p 37-43.

Jakubauskas, M., K. Kindscher, and D. DeBinski. 2001. Spectral and biophysical relationships of montane sagebrush communities in multi-temporal SPOT XS data. International Journal of Remote Sensing 22:1767-1778.

Jianlong, L., L. TIANGang, AND C. Quangong. 1998. Estimating grassland yields using remote sensing and GIS technologies in China. New Zealand Journal of Agricultural Research 41:31-38.

Lass, L. W., H. W. Carson, and R. H. Callihan. 1996. Detection of yellow starthistle (Centuarea solstitialis) and common St. Johnswort (Hypericum perforatum) with multispectral digital imagery. Weed Technology 10:466-474.

Lass, L. W., and R. H. Callihan. 1997. The effect of phenological stage on deductibility of yellow hawkweed (hieracium pretense) and 0xeye daisy (Chrysanthemum leucanthemum) with remote multispectral digital imagery. Weed Technology 11:248-256.

Lass, L. W., C. T. Donald, B. Shafi, and T. S. Prather. 2002. Detecting spotted knapweed (Centaurea maculosa) with hyperspectral remote sensing technology. Weed Technology 16:426-432.

Lawrence, R. L., And W. J. Ripple. 1998. Comparisons among vegetation indices and bandwise regression in a highly disturbed, heterogeneous landscape: Mount St. Helens, Washington. Remote Sensing of Environment 64:91-102.

McCarTY, M. 1982. Musk thistle (Carduus thoermeri) seed production. Weed Science 30:441-445.

McGwire, K., T. MinoR, And L. Fenstermaker. 2000. Hyperspectral mixture modeling for quantifying sparse vegetation cover in arid environments. Remote Sensing of Environment 72:360-374.

Mirik, M., J. E. Norland, R. L. Crabtree, and M. E. Biondinı. 2005. Hyperspectral one-meter-resolution remote sensing in Yellowstone National Park, Wyoming: I. Forage nutritional values. Rangeland Ecology and Management 58:452-452.

Parker Williams, A., and E. R. Hunt, JR. 2002. Estimation of leafy spurge cover from hyperspectral imagery using mixture tuned match filtering. Remote Sensing of Environment 82:446-456.

Rees, N. E., J. L. Littlefield, W. I. Bruckart, and A. Baudion. 1996. Musk thistle, Carduus nutans (group). In: N. E. Rees, P. C. Quimby, Jr., G. L. Piper, E. M. Coombs, C. E. Turner, N. R. Spencer, and L. V. Knutson [EDS.]. Biological control of weeds in the West, section II. Bozeman, MT: Western Society of Weed Science Press.

Roduner, M., G. Cuperus, P. Mulder, J. Stritzke, and M. Payton. 2003. Successfu biological control of the musk thistle in Oklahoma using the musk thistle head weevil and the rosette weevil. American Entomologist 49:112-120.

Shibayama, M. AND T. AkiYama. 1991. Estimating grain yield of maturing rice canopies using high spectral resolution reflectance measurements. Remote Sensing of Environment 36:45-53.

Shibayama, M., W. Takahashi, S. Morinaga, and T. Akiyama. 1993. Canopy water deficit detection in paddy rice using high resolution field spectroradiometer Remote Sensing of Environment 45:117-126.

Simon, S. 2005. Log transformation. Available at: http://www.cmh.edu/stats/ model/linear/log.asp. Accessed 24 August 2005.

S-PLUS. 2001. S-PLUS 6 for Windows guide to statistics. Vol. 1. Seattle, WA: Insightful Inc.

[SAS] Statistical Analysis Systems. 2003. SAS 9 for Windows. Cary, NC: Statistical Analysis Systems Institute Inc.

Thenkaball, P. S., R. B. Smith, and E. D. Pauw. 2000. Hyperspectral vegetation indices and their relationships with agricultural crop characteristics. Remote Sensing of Environment 71:158-182.

Whitson, T. D., L. C. Burrill, S. A. Dewey, D. W. Cudney, B. E. Nelson, R. D. Lee, and R. Parker. 1991. Musk thistle, Carduus nutans L. In: T. D. Whitson [ed.] Weeds of the West. Jackson, WY: Western Society of Weed Science Press. p 76-77. 